OPEN ACCESS

Edited by:

Hailiang $\mathrm{Hu}$,

Duke University, United States

Reviewed by:

Zoltán S. Zádori,

Semmelweis University, Hungary

Zhijun Dai,

Zhejiang University, China

*Correspondence:

Hang Zheng

734679158@qq.com

tThese authors share first authorship

Specialty section:

This article was submitted to Pharmaceutical Medicine and

Outcomes Research,

a section of the journal

Frontiers in Pharmacology

Received: 10 September 2019 Accepted: 08 November 2019 Published: 27 November 2019

Citation:

Li B-H, Yu Z-J, Wang C-Y, Zi H, Li X-D, Wang X-H, Ren X-Y, LiU T-Z and Zheng $H$ (2019) A Preliminary,

Multicenter, Prospective and Real World Study on the Hemostasis,

Coagulation, and Safety of Hemocoagulase Bothrops Atrox in Patients Undergoing Transurethral Bipolar Plasmakinetic Prostatectomy.

Front. Pharmacol. 10:1426.

doi: 10.3389/fphar.2019.01426

\section{A Preliminary, Multicenter,} Prospective and Real World Study on the Hemostasis, Coagulation, and Safety of Hemocoagulase Bothrops Atrox in Patients Undergoing Transurethral Bipolar Plasmakinetic Prostatectomy

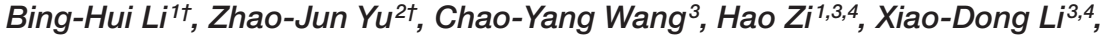 \\ Xing-Huan Wang ${ }^{1}$, Xuan-Yi Ren ${ }^{5}$, Tong-Zu Liu ${ }^{1}$ and Hang Zheng ${ }^{1 *}$ on behalf of the \\ BPSC investigators
}

\begin{abstract}
${ }^{1}$ Department of Urology, Zhongnan Hospital of Wuhan University, Wuhan, China, ${ }^{2}$ Medical Department of Graduate School, Nanchang University, Nanchang, China, ${ }^{3}$ Center for Evidence-Based Medicine, Institute of Evidence-Based Medicine and Knowledge Translation, Henan University, Kaifeng, China, ${ }^{4}$ Department of Urology, Huaihe Hospital of Henan University, Kaifeng, China, ${ }^{5}$ Department of Urology, Kaifeng Central Hospital, Kaifeng, China
\end{abstract}

Objective: To evaluate the hemostasis and coagulation effect of Hemocoagulase Bothrops Atrox in benign prostatic hyperplasia (BPH) patients undergoing transurethral bipolar plasmakinetic prostatectomy (TUPKP).

Methods: This study adopted a multicenter, prospective, and real world design. BPH patients undergoing TUPKP were divided into two groups according to whether they adopted Hemocoagulase Bothrops Atrox (group B) or not (group A) during perioperative period. The electronic clinical data on every included subject, including the international prostate symptom score (IPSS) and the quality of life scale (QoL), maximum urinary flow rate (Qmax), complete blood count, coagulation screening test and adverse events, were measured and compared between the two groups.

Results: Finally, 695 patients, 443 in group A and 252 in group B were included. Baseline characteristics showed no significant difference between two groups. In group A, compared with baseline, IPSS decreased 15.66 (95\% Cl $=-16.45$ to -14.87 ), QoL decreased $3.08(95 \% \mathrm{Cl}=-3.30$ to -2.87$)$, prothrombin time prolonged $1.02 \mathrm{~s}(95 \%$ $\mathrm{Cl}=0.56$ to 1.48), while white blood cells, neutrophils, lymphocytes, and hemoglobin also significantly changed; white blood cells, neutrophils and platelets increased, while lymphocytes decreased by $0.14 \times 109 / \mathrm{L}(95 \% \mathrm{Cl}=-0.21$ to -0.08$)$ before discharge. In group B, compared with baseline, IPSS decreased $16.12(95 \% \mathrm{Cl}=-17.02$ to -15.21$)$, QoL decreased 3.32 (95\% Cl $=-3.56$ to -3.07$)$, and white blood cells, neutrophils, lymphocytes, and hemoglobin were also significantly changed, along with white blood cells and lymphocytes that tested before discharge $(p<0.01)$; however, prothrombin time was not significant prolonged $(\mathrm{MD}=0.48,95 \% \mathrm{Cl}=-0.05$ to 1.01$)$. When compared with 
group $A$ and group $B$, the average hospitalization time in group $A$ was longer than group $B(p<0.01)$, transfusion risk was similar in the two groups $(O R=1.582,95 \% \mathrm{Cl}=0.552$ to 4.538). Parameters had no substantial difference between the two subgroups whether prostate volume was more than $80 \mathrm{~mL}$ or not.

Conclusion: Our study indicated that Hemocoagulase Bothrops Atrox can shorten the prothrombin time, hospitalization time and is probably safe among BPH patients undergoing TUPKP, exhibiting fine hemostasis and coagulation efficacy, and would not be influenced by prostate volume.

Keywords: benign prostatic hyperplasia, transurethral bipolar plasmakinetic prostatectomy, hemocoagulase bothrops atrox, hemostasis, blood transfusion, coagulation, real world study

\section{INTRODUCTION}

Benign prostatic hyperplasia (BPH) is a leading cause of lower urinary tract symptoms (LUTS) and a common benign disease among males, showing an upward prevalence with age. There are multiple options in treating $\mathrm{BPH}$, including drug, surgical and minimally invasive options (Vuichoud and Loughlin, 2015; Chughtai et al., 2016). Transurethral resection of the prostate (TURP) is a common method in treating BPH, but perioperative complications, such as intraoperative bleeding and transurethral resection syndrome (TURS), still exhibit a relatively high incidence. In recent years, transurethral bipolar plasmakinetic prostatectomy (TUPKP) has been used in this field, reaching better hemostasis and showing less TURS than TURP (Ran et al., 2013). However, prostate-surrounding tissue contains large venous sinuses, which tend to breach during surgery, thus leading to complications such as bleeding and affecting the operation (de Medicis, 2014). Hemostatic agent can be used during perioperative period to reduce bleeding. Reportedly, tranexamic acid is beneficial for reducing perioperative blood loss in TURP (Meng et al., 2019). But rarely studies clarified the role of thrombin in TUPKP. Hence, this study aimed to evaluate the effect and safety of a commonly used hemostatic agent (Hemocoagulase Bothrops Atrox for injection) (Wei et al., 2010; Lu et al., 2017) in BPH patients with TUPKP, through examining prostate indicators and hematological parameters.

\section{METHODS}

\section{Study Design and Subjects}

This study adopted a multicenter, prospective, and real world design for preliminary investigation. The subjects were selected from the Bladder Cancer and Benign Prostatic Hyperplasia Study in Chinese Population (BPSC), a prospective study reported previously (Zeng et al., 2018a; Zeng et al., 2018b; Zeng et al., 2018c; Wu et al., 2019; Zhao et al., 2019; Zi et al., 2019), which from September 2016 to November 2018. Eligible patients were confirmed with BPH and underwent TUPKP. Patients with urinary malignancies, urinary tract infections and abnormal coagulation function were excluded. Eventually included patients were divided into two groups according to whether they used Hemocoagulase Bothrops Atrox for Inject (brand name: baquting; production lot number: H20041419) (group B) or not during perioperative period (group A). Electronic clinical data on every included subject were retrospectively analyzed. This study was reviewed and approved by the Committee for Ethical Affairs of the Zhongnan Hospital of Wuhan University (Approval No. 2016028). All participants signed written informed consent before enrollment.

\section{Measurements and Data}

Detailed medical histories for all patients were collected, including age, height, weight, body mass index (BMI), history of smoking, and history of alcohol intake. Physical examination results and detailed medical data were recorded, including clinical blood pressure, fasting blood glucose (FBG, $\mathrm{ng} / \mathrm{mL}$ ), prostate ultrasound, maximum urinary flow rate (Qmax), complete blood count (CBC), and coagulation screening test results. In addition, international prostate symptom score (IPSS) and the quality of life (QoL) scale were used to assess LUTS and perceptions of quality of life.

BMI $(\mathrm{kg} / \mathrm{m} 2)$ was calculated through weight in kilograms divided by height in meters squared; systolic blood pressure $(\mathrm{SBP}, \mathrm{mmHg})$ and diastolic blood pressure (DBP, $\mathrm{mmHg}$ ) were measured following the way recommended by the American Heart Association guidelines (Pickering et al., 2005). The largest anteroposterior height $(\mathrm{H}, \mathrm{cm})$, transverse width $(\mathrm{W}, \mathrm{cm})$, and cephalocaudal length $(\mathrm{L}, \mathrm{cm})$ of prostate were measured through prostate ultrasound, and prostate volume $(\mathrm{PV}, \mathrm{mL})$ was calculated using the ellipsoid formula $P V=\frac{\pi}{6} \times H \times W \times L$ (Eri et al., 2002). Qmax $(\mathrm{ml} / \mathrm{s})$ was measured via flow rate test, along with IPSS and QoL, and recorded as indicators for assessing the patient's prostate symptom. White blood cells (WBC, $\times 109 / \mathrm{L})$, neutrophils $(\times 109 / \mathrm{L})$, platelets $(\times 109 / \mathrm{L})$, lymphocytes $(\times 109 / \mathrm{L})$ and hemoglobin were determined based on $\mathrm{CBC}$. The results of activated partial thromboplastin time (APTT, s), prothrombin time (PT, s), thrombin time (TT, s) and fibrinogen $(\mathrm{g} / \mathrm{L})$ level were obtained from routine blood coagulation tests. The results of IPSS, Qmax, QoL, APTT, platelets, TT and fibrinogen were recorded at the admission and after operation, while those for WBC, neutrophils, platelets, lymphocytes and hemoglobin were recorded at the admission, after 
operation and before discharge. The data recorded at the admission were considered as baselines. In addition, hospitalization time was also extracted.

\section{Statistical Analysis}

Continuous variables were expressed as mean and standard deviation (SD), while categorical ones as percentage. We compared age, height, weight, BMI, PV, history of smoking, history of alcohol intake, SBP, DBP, FBG, and hospitalization time between group A and group B. Student's t-test was used for continuous variables and chi-squared tests for categorical ones. Adjusted mean changes in IPSS, Qmax, QoL, APTT, PT, TT, and fibrinogen level after operation from baseline, along with $95 \%$ confidence interval $(95 \% \mathrm{CI})$, were calculated. WBC, neutrophils, platelets, lymphocytes and hemoglobin levels after operation and at discharge were compared with baseline ones, and mean changes were calculated. Meanwhile, two subgroups were divided with $\mathrm{PV}$ at $80 \mathrm{ml}$ as the threshold, and the mean difference in each parameter was calculated separately. Differences in mean change between group $\mathrm{A}$ and group $\mathrm{B}$ were calculated. In addition, the association between blood transfusion and hemostatic agent during the operation was explored. We computed odds ratios (OR) and 95\% CI using binary logistic regression model or ordinal logistic regression model. All effect values except subgroup were adjusted for age, BMI, PV, history of smoking, history of drinking, SBP, DBP and FBG. We only offered unadjusted subgroup results here without further analysis. All analyses were carried out using the SAS software, version 9.4 TS1M6 (SAS Institute Inc, Cary, NC).

\section{RESULTS}

\section{Participants' Characteristics}

A total of 695 patients were included in this study. Of the cases, 443 did not use Hemocoagulase Bothrops Atrox for Inject (group A) while 252 did during the perioperative period (group B). The baseline characteristics of all patients were presented in Table 1. The mean SBP was $134.28 \pm 17.14 \mathrm{mmHg}$ and $131.53 \pm$ $16.00 \mathrm{mmHg}(\mathrm{p}=0.04)$ for the two groups, respectively. The mean age reached $72.76 \pm 7.60$ years and $71.94 \pm 7.24$ years for the two groups, without statistically significant difference $(\mathrm{p}=$ 0.17). Likewise, there was no significant difference between the two groups in height, weight, BMI, PV, history of smoking, history of alcohol intake, DBP or FBG (all p > 0.05).

\section{Overall Results}

Table 2 showed prostate indicators, $\mathrm{CBC}$ and coagulation screening test results for the groups $\mathrm{A}$ and $\mathrm{B}$. The results of prostate indicators, $\mathrm{CBC}$ and coagulation screening test were also compared with baseline ones.

Accordingly, IPSS decreased 15.66 (95\% CI $=-16.45$ to -14.87 , $\mathrm{p}<0.01$ ), QoL decreased 3.08 (95\% CI $=-3.30$ to $-2.87, \mathrm{p}<0.01$ ), PT prolonged $1.02 \mathrm{~s}(95 \% \mathrm{CI}=0.56$ to $1.48, \mathrm{p}<0.01)$, while $\mathrm{WBC}$, neutrophils, lymphocytes, and hemoglobin also changed significantly in group A $(\mathrm{p}<0.001)$. However, Qmax, platelets, APTT, TT and
TABLE 1 | Baseline characteristics of benign prostatic hyperplasia patients not use and use Hemocoagulase Bothrops Atrox for inject.

\begin{tabular}{|c|c|c|c|}
\hline Baseline & $\begin{array}{l}\text { Without use (Group } \\
\text { A) }(n=443)\end{array}$ & $\begin{array}{l}\text { With use (Group B) } \\
\qquad(\mathrm{n}=252)\end{array}$ & P-value \\
\hline Age (years) & $72.76 \pm 7.60$ & $71.94 \pm 7.24$ & 0.1665 \\
\hline $\begin{array}{l}\text { Prostate volume } \\
(\mathrm{mL})\end{array}$ & $68.19 \pm 37.18$ & $62.75 \pm 37.57$ & 0.0652 \\
\hline $\begin{array}{l}\text { Prostate volume } \\
(\mathrm{mL})\end{array}$ & & & 0.4107 \\
\hline$>80 \mathrm{~mL}$ & 138(31.15\%) & 181(71.83\%) & \\
\hline$<=80 \mathrm{~mL}$ & $305(68.85 \%)$ & $71(28.17 \%)$ & \\
\hline Height (cm) & $168.46 \pm 5.82$ & $168.63 \pm 5.33$ & 0.7070 \\
\hline Weight (kg) & $65.95 \pm 10.60$ & $66.47 \pm 11.52$ & 0.5569 \\
\hline $\begin{array}{l}\text { Body mass index } \\
\left(\mathrm{kg} / \mathrm{m}^{2}\right)\end{array}$ & $23.26 \pm 3.43$ & $23.35 \pm 3.95$ & 0.7625 \\
\hline $\begin{array}{l}\text { History of smoking } \\
(\mathrm{n}[\%])\end{array}$ & $122(35.57 \%)$ & $76(30.16 \%)$ & 0.166 \\
\hline $\begin{array}{l}\text { History of alcohol } \\
\text { intake }(n[\%])\end{array}$ & $84(24.56 \%)$ & $67(26.91 \%)$ & 0.518 \\
\hline $\begin{array}{l}\text { Systolic blood } \\
\text { pressure (mmHg) }\end{array}$ & $134.28 \pm 17.14$ & $131.53 \pm 16.00$ & 0.0381 \\
\hline $\begin{array}{l}\text { Diastolic blood } \\
\text { pressure }(\mathrm{mmHg})\end{array}$ & $79.39 \pm 10.36$ & $78.57 \pm 10.57$ & 0.3231 \\
\hline $\begin{array}{l}\text { Hypertension } \\
\text { status (n[\%]) }\end{array}$ & & & 0.147 \\
\hline No & $373(85.35 \%)$ & $224(89.24 \%)$ & \\
\hline Yes & $64(14.65 \%)$ & $27(10.76 \%)$ & \\
\hline $\begin{array}{l}\text { Fasting blood } \\
\text { glucose (ng/mL) }\end{array}$ & $5.36 \pm 1.51$ & $5.41 \pm 1.32$ & 0.6929 \\
\hline
\end{tabular}

fibrinogen were not significantly different from baseline values $(\mathrm{p}>$ 0.05). CBC was re-examined before discharge. The results showed that compared with baseline figures, WBC, neutrophils and platelets increased while lymphocytes decreased $0.14 \times 109 / \mathrm{L}(95 \% \mathrm{CI}=-0.21$ to $-0.08, \mathrm{p}<0.01)$, all statistically significant $(\mathrm{p}<0.05)$.

In group B, IPSS decreased $16.12(95 \% \mathrm{CI}=-17.02$ to -15.21 , $\mathrm{p}<0.01)$, QoL decreased $3.32(95 \% \mathrm{CI}=-3.56$ to $-3.07, \mathrm{p}<0.01)$, while WBC, neutrophils, lymphocytes, and hemoglobin were also changed significantly, along with WBC and lymphocytes that tested before discharge $(\mathrm{p}<0.01)$. However, Qmax, platelets, APTT, PT, TT, and fibrinogen after operation, as well as WBC and neutrophils before discharge, were not significantly different from baseline values $(\mathrm{p}>0.05)$.

In addition, we compared mean change in each outcome indicator between groups $\mathrm{A}$ and $\mathrm{B}$, and adjusted for age, BMI, PV, history of smoking, history of drinking, SBP, DBP and FBG. Adjusted results showed that there was no significant difference in mean changes for IPSS, Qmax, QoL, WBC, neutrophils, platelets, lymphocytes, APTT, PT, TT, or fibrinogen between the two groups $(\mathrm{p}>0.05)$. The average hospitalization time in group A was longer than that in group B (8.20 \pm 3.09 days vs. $6.56 \pm 3.60$ days, $\mathrm{p}<0.01)$.

Table 3 summarized the results of univariate and multivariate logistic regression analyses. In unadjusted analysis, not using this drug had no substantial association with transfusion risk $(\mathrm{OR}=$ $1.827,95 \% \mathrm{CI}=0.764-4.369, \mathrm{p}=0.18$ ). After adjustment for age, BMI, PV, history of smoking, history of drinking, SBP, DBP, and FBG, Hemocoagulase Bothrops Atrox adopting was also not 
TABLE 2 | Effects of Hemocoagulase Bothrops Atrox for inject on prostatic parameters and biochemical indexes in two groups.

\begin{tabular}{|c|c|c|c|c|c|c|c|c|}
\hline \multirow[t]{2}{*}{ Outcomes } & \multicolumn{3}{|c|}{ Group A } & \multicolumn{3}{|c|}{ Group B } & \multirow{2}{*}{$\begin{array}{c}\text { Adjusted difference } \\
\text { in mean change }(95 \% \\
\mathrm{Cl})\end{array}$} & \multirow[t]{2}{*}{$p$} \\
\hline & Baseline & $\begin{array}{l}\text { Mean change } \\
(95 \% \mathrm{Cl})\end{array}$ & $\boldsymbol{P}$ & Baseline & Mean change $(95 \% \mathrm{Cl})$ & $p$ & & \\
\hline \multicolumn{9}{|l|}{ After operation } \\
\hline IPSS & \multicolumn{2}{|c|}{$23.25 \pm 6.56-15.66(-16.45,-14.87)$} & $<0.001$ & $24.39 \pm 5.88$ & $-16.12(-17.02,-15.21)$ & $<0.001$ & $0.45(-0.54,1.44)$ & 0.368 \\
\hline Qmax (ml/s) & $7.59 \pm 5.71$ & 4.26(-2.32,10.85) & 0.2 & $9.06 \pm 5.32$ & $5.85(-1.47,13.16)$ & 0.115 & $-1.58(-8.32,5.16)$ & 0.641 \\
\hline Quality of Life & $4.93 \pm 0.86$ & $-3.08(-3.30,-2.87)$ & $<0.001$ & $4.75 \pm 1.00$ & $-3.32(-3.56,-3.07)$ & $<0.001$ & $0.23(-0.03,0.50)$ & 0.085 \\
\hline White blood cells (×10\%/L) & $6.36 \pm 1.98$ & $3.09(2.63,3.56)$ & $<0.001$ & $6.43 \pm 2.35$ & $2.99(2.47,3.50)$ & $<0.001$ & $0.11(-0.44,0.65)$ & 0.699 \\
\hline Neutrophils (×109/L) & $4.22 \pm 1.85$ & $3.45(3.00,3.91)$ & $<0.001$ & $4.23 \pm 2.24$ & $3.40(2.91,3.90)$ & $<0.001$ & $0.05(-0.47,0.57)$ & 0.854 \\
\hline Platelets (×109/L) & $\begin{array}{c}190.01 \pm \\
59.99\end{array}$ & $-5.43(-11.70,0.85)$ & 0.09 & $180.03 \pm 60.81$ & $-4.08(-10.95,2.78)$ & 0.243 & $-1.34(-8.65,5.96)$ & 0.718 \\
\hline Lymphocytes (×109/L) & $1.56 \pm 0.95$ & $-0.35(-0.45,-0.25)$ & $<0.001$ & $1.48 \pm 0.53$ & $-0.42(-0.54,-0.31)$ & $<0.001$ & $0.07(-0.05,0.19)$ & 0.224 \\
\hline Hemoglobin (g/L) & $\begin{array}{c}134.73 \pm \\
17.20\end{array}$ & $-10.36(-12.28,-8.45)$ & $<0.001$ & $131.24 \pm 15.56$ & $-11.57(-13.67,-9.47)$ & $<0.001$ & $1.21(-1.02,3.44)$ & 0.288 \\
\hline APTT (s) & $33.24 \pm 5.08$ & $0.67(-1.60,2.95)$ & 0.549 & $32.41 \pm 4.60$ & $0.99(-1.63,3.62)$ & 0.445 & $-0.32(-3.41,2.77)$ & 0.834 \\
\hline Prothrombin time (s) & $12.62 \pm 6.06$ & $1.02(0.56,1.48)$ & $<0.001$ & $11.56 \pm 1.48$ & $0.48(-0.05,1.01)$ & 0.074 & $0.54(-0.09,1.17)$ & 0.089 \\
\hline Thrombin time (s) & $15.73 \pm 2.05$ & $-0.55(-2.43,1.32)$ & 0.547 & $14.68 \pm 2.34$ & $-0.10(-2.38,2.18)$ & 0.928 & $-0.45(-2.82,1.91)$ & 0.694 \\
\hline Fibrinogen (g/L) & $3.24 \pm 0.84$ & $0.06(-0.32,0.44)$ & 0.75 & $3.29 \pm 0.91$ & $-0.22(-0.68,0.23)$ & 0.319 & $0.28(-0.22,0.79)$ & 0.262 \\
\hline \multicolumn{9}{|l|}{ Before discharge } \\
\hline White blood cells $\left(\times 10^{9} / \mathrm{L}\right)$ & $6.36 \pm 1.98$ & $0.35(0.00,0.69)$ & 0.047 & $6.43 \pm 2.35$ & $0.17(-0.18,0.52)$ & 0.333 & $0.17(-0.20,0.55)$ & 0.365 \\
\hline Neutrophils (×109/L) & $4.22 \pm 1.85$ & $0.39(0.08,0.70)$ & 0.013 & $4.23 \pm 2.24$ & $0.18(-0.14,0.49)$ & 0.269 & $0.21(-0.13,0.55)$ & 0.221 \\
\hline Platelets (×109/L) & $\begin{array}{c}190.01 \pm \\
59.99\end{array}$ & $23.43(13.77,33.10)$ & $<0.001$ & $180.03 \pm 60.81$ & $14.50(4.58,24.42)$ & 0.004 & $8.93(-1.71,19.57)$ & 0.1 \\
\hline Lymphocytes (×10\%/L) & $1.56 \pm 0.95$ & $-0.14(-0.21,-0.08)$ & $<0.001$ & $1.48 \pm 0.53$ & $-0.15(-0.22,-0.08)$ & $<0.001$ & $0.01(-0.07,0.08)$ & 0.888 \\
\hline Hospitalization time (days) & \multicolumn{3}{|l|}{$8.20 \pm 3.09$} & \multicolumn{3}{|l|}{$6.56 \pm 3.60$} & & $<0.001$ \\
\hline
\end{tabular}

Cl, confidence interval; IPSS: International Prostate Symptom Score; Qmax, maximum urinary flow rate; APTT, activated partial thromboplastin time.

TABLE 3 | Effect of Hemocoagulase Bothrops Atrox for inject on blood transfusion during operative.

\begin{tabular}{|c|c|c|c|c|c|c|}
\hline Transfusion & Group A ( $n=443)$ & Group B (n = 252) & Crude OR $(95 \% \mathrm{Cl})$ & $p$ & Adjusted OR $(95 \% \mathrm{Cl})^{*}$ & $p$ \\
\hline No & $432(97.52 \%)$ & $241(95.63 \%)$ & $1.827(0.764,4.369)$ & 0.176 & $1.582(0.552,4.538)$ & 0.394 \\
\hline Yes & $11(2.48 \%)$ & $11(4.37 \%)$ & & & & \\
\hline
\end{tabular}

OR, odds ratio; $\mathrm{Cl}$, confidence interval.

*, Adjustment for age, body mass index, prostate volume, history of smoking, history of drinking, systolic blood pressure, diastolic blood pressure, and fasting blood glucose.

associated with transfusion risk either $(\mathrm{OR}=1.582,95 \% \mathrm{CI}=$ 0.552-4.538, $\mathrm{p}=0.39$ ).

\section{Subgroup Analyses}

In order to investigate the influence of PV size, we divided the patients into two groups, $\mathrm{PV}>80 \mathrm{ml}$ and $\mathrm{PV} \leq 80 \mathrm{ml}$. Figure 1 showed prostate indicators, $\mathrm{CBC}$ and coagulation screening test results for each subgroup, revealing no significant difference between these two groups.

\section{DISCUSSION}

The study was based on $695 \mathrm{BPH}$ patients receiving TUPKP; of them, 443 did not use hemostatic agents while 252 did during perioperative period. As a result, IPSS, QoL, WBC, neutrophils and lymphocytes in both two groups and PT in group A showed significantly alterations after operation. There was no significant difference between the two groups in Qmax, platelets, APTT, TT, or fibrinogen or in PT for group B after operation. Furthermore, $\mathrm{CBC}$ before discharge was compared with the baseline. The results showed that WBC and neutrophils in group A before discharge were higher than baseline figures. There were significant differences in platelets and lymphocytes of the two groups from the baseline, but not in WBC or neutrophils in group $\mathrm{B}$ from the baseline.

$\mathrm{BPH}$, a benign urinary system disease, is affected by many factors, and its prevalence increases with age in males (Berry et al., 1984; Park et al., 2018). It is one of the common diseases in middle-aged and elderly men, and causes a huge burden (Saigal and Joyce, 2005; Speakman et al., 2015). An epidemiological survey on BPH in rural areas in Zhengzhou (a city in central China) showed that the prevalence of $\mathrm{BPH}$ was $10.04 \%$, and with age increasing this figure increased from $2.17 \%$ in individuals aged $40-44$ years to $31.11 \%$ in those 80 years or older (Yue et al., 2019), which were consistent with findings from a meta-analysis (Wang et al., 2015b) and a survey 

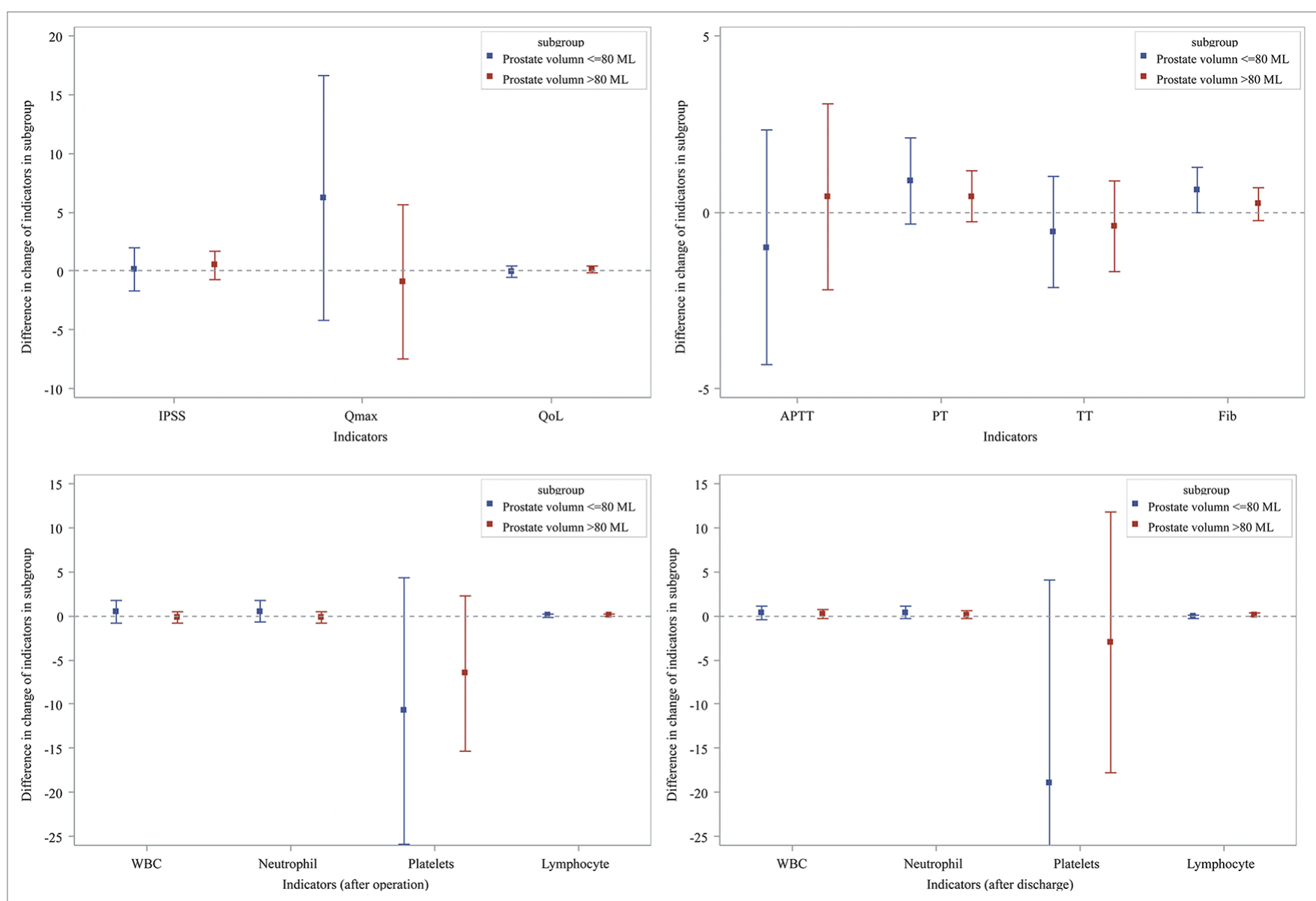

FIGURE 1 | Subgroup analysis effects of Hemocoagulase Bothrops Atrox for inject on prostatic parameters and biochemical indexes.

in Europe (Foster et al., 2015). Main clinical symptoms refer to LUTS, including frequent micturition, urinary urgency, urination inability, trouble in urination starting, etc (Martin et al., 2011; Ho et al., 2018). The process of BPH is slow, and early symptoms are not typical. As the lower urinary tract obstruction worsens, symptoms gradually become apparent. Appropriate treatments are generally selected based on patient's LUTS and decline in QoL, including conservative treatment, pharmacological treatment and surgical treatment (Gravas et al., 2018). Surgery is widely used as an effective way to treat BPH. Surgical methods include open prostatectomy (Saluja et al., 2018), transurethral vaporization of the prostate (TUVP) (Littlejohn et al., 2004), TUPKP (He et al., 2016; Zeng et al., 2018a), and prostate laser surgery (Ketan and Prashant, 2016; Jhanwar et al., 2017).

The TURP may have multiple complications, the most common is bleeding; hence, in many cases, blood transfusion may be needed (Mebust et al., 1989; Doll et al., 1992; Berger et al., 2004). The most terrible complication of conventional TURP is TURS. The incidence of TURS varies greatly from $0.18 \%$ to $10.9 \%$ (Koshiba et al., 1995). TUPKP is one of the most widely used methods in treating BPH (Martis et al., 2008;
Autorino et al., 2009; Muslumanoglu et al., 2012; Li et al., 2015). At present, TUPKP has great advantages in reducing the incidence of traditional TURP complications. Many studies have confirmed the application of plasma bipolar systems in TURP (Botto et al., 2001; Dincel et al., 2004). A number of studies have shown that plasma bipolar systems are as effective as traditional TURP in treating symptoms associated with $\mathrm{BPH}$, and are safer in perioperative and postoperative complications. In a French study, 42 patients with BPH were enrolled. At 3 months after TUPKP, the mean Qmax increased from 7.9 to $19.7 \mathrm{~mL} / \mathrm{s}$, and the score for IPSS decreased from 16 to 9 . There was no postoperative bleeding event, the average indwelling urethral catheter time was 1.4 days, and the average hospitalization time was 2.2 days (Botto et al., 2001). In addition, some studies have shown that TUPKP can reduce the adverse effects of surgery on patients, such as the catheterization time reduced $44 \%$, hospitalization time decreased $43 \%$, acute complications decreased 52\%, and long-term complications reduced 30\% (Starkman and Santucci, 2005). However, in a one-year follow-up study, the efficacy and safety of TURP and TUPKP were compared, there was no significant difference in the residual volume, Qmax, 
IPSS, QoL, hospitalization time and catheterization time between the two groups. The proportion of reinsertion was higher in the TUPKP group (30\% vs. 5\%). In TURP group, the clot evacuation rate was higher ( $19 \%$ vs. 0$)$, because of the hemostatic advantage of TUPKP (Dunsmuir et al., 2003). The results of several studies showed that the operation time of TUPKP is about 39 minutes to 56 minutes, the intraoperative bleeding volume is $144 \mathrm{~mL}$ to $174 \mathrm{~mL}$, and the incidence of postoperative bleeding is $1.47 \%$ to $3.3 \%$ (El-Shaer et al., 2017; Liu et al., 2017; Zou et al., 2018). According to several meta-analyses, the probability of TUPKP requiring blood transfusion is $1.14 \%$ to $1.85 \%$ (Mamoulakis et al., 2009; Li et al., 2015; Wang et al., 2015a). Although it has the advantages of less trauma and less bleeding (Chen et al., 2014), bleeding is still a problem that cannot be ignored (Chen et al., 2013). Because the hyperplastic prostate tissue is contained in a dense capsule, it seems to accumulate high pressure in the prostate tissue, which may lead to continuous bleeding after the blood vessels are cut during the prostatectomy (Berger et al., 2005).

The technology of TUPKP is relatively mature. In our research, IPSS and QoL showed significant changes after operation. But for elderly patients, some phenomenon such as poor vascular function may cause prolonged bleeding time, and the chance of developing postoperative complications increases. Hence, during perioperative period, hemostatic agents may be used to prevent or treat bleeding from surgical wounds. Hemostatic agents are widely used in clinical practice, such as abdominal surgery (Wei et al., 2010), orthopedic surgery (Qiu et al., 2017), oral surgery (Joshi et al., 2014), etc. In addition, hemostatic agents are often used to prevent or treat perioperative bleeding in prostatectomy. A study in the United States analyzed the using rate of hemostatic agents in patients undergoing major surgery who were recorded in the Perspective database from 2000 to 2010 (Wright et al., 2014). The results showed that the use of hemostatic agents increased year by year in the past 10 years, reaching $35.2 \%$ in 2010 . The use of hemostatic agents in prostatectomy was $13.7 \%$, while the transfusion rate for prostatectomy decreased to $6.6 \%$. Common hemostatic agents contained Hemocoagulase Agkistrodon (Wei et al., 2010), Hemocoagulase Bothrops Atrox (Petretski et al., 2000), and Hemocoagulase Atrox for Injection (Zhou, 2017). Hemostatic agents' functioning is a complex process. Hemostatic agents improve hemostasis through stimulating fibrin formation or inhibiting fibrinolysis (Levi et al., 2002).

According to the results of coagulation screening test after operation, we found an interesting phenomenon: PT was prolonged in patients who did not use hemostatic agents, while postoperative PT in patients who used hemostatic agents did not change significantly from baseline. Therefore, Hemocoagulase Bothrops Atrox for Inject may shorten the activation time of prothrombin, accelerate thrombin formation, activate thrombin-activated fibrinolytic inhibitors and promote blood coagulation. An in vitro experiment (Li et al., 2018) was conducted to explore the mechanism of Hemocoagulase, and the results showed that Hemocoagulase could promote blood coagulation via hydrolyzing fibrinogen into easily absorbed regions and inhibit the activation of plasminogen, thereby reducing the risk of thrombosis.
The prostate has an extensive plexus of venous sinuses, so bleeding risk exists during or after surgery. Although massive hemorrhage shows very low incidence rate, it is still a serious complication of TURP (Xie et al., 2012). When massive hemorrhage occurs, transfusion is an effective treatment. Reportedly, the transfusion rate is about $0.9-2.9 \%$ (Reich et al., 2008; Ahmad et al., 2016). The absence of hemostatic agents in this study did not increase the chances of blood transfusion. The reasons may be complex. On the one hand, it may be related to the low rate of massive bleeding of $\mathrm{BPH}$. Most patients experienced little intraoperative or postoperative bleeding volume. After physical treatment, such as catheter compression, better therapeutic effect can be obtained (Bah and Green, 2018). On the other hand, TURP and TUPKP are both the standard operation for BPH. Their effectiveness and safety have been verified by a large number of clinical trials and applications, and the incidence of massive hemorrhage caused by surgery is relatively low (Qian et al., 2017; Babayan, 2018; Jiang and Qian, 2019).

In addition, there are some studies that focus on the effectiveness and safety of TUPKP applications to specific populations. Some studies have performed TUPKP on 193 highrisk elderly patients. The intraoperative blood loss is $42.6 \pm$ $19.5 \mathrm{~mL}$, the risk of postoperative secondary bleeding is $1.6 \%$, and the risk of postoperative blood transfusion is about $0.5 \%$ (Lv et al., 2012). For patients with large gland, there are many studies reported that the postoperative hemoglobin decreased from 0.65 to $1.63 \mathrm{~g} / \mathrm{dL}$ (Huang et al., 2015; Zhang et al., 2015; Wu et al., 2016), and there is still a greater risk of bleeding during the operation. For patients taking anticoagulants, results show that TUPKP can greatly improve LUTS of patients, and is a safe and effective minimal treatment option, but its reported blood transfusion rate is $2.2 \%$, higher than that of ordinary patients ( $\mathrm{Li}$ et al., 2015; Wang et al., 2015a; El-Shaer et al., 2017). Interestingly, the results of this study show that use of Hemocoagulase Bothrops Atrox can reduce the hospitalization time without altering the patient's coagulation parameters and the results of the complete blood count. The reliability of the results of this study was further verified: Hemocoagulase Bothrops Atrox is safe for patients with $\mathrm{BPH}$ who undergoing TUPKP. Therefore, in clinical practice, clinicians can prevent thrombosis by using Hemocoagulase Bothrops Atrox in a preventive manner according to the patient's physical condition, such as high-risk elderly patients, patients with large gland, and patients taking anticoagulants. The use of Hemocoagulase Bothrops Atrox can reduce the hospitalization time, decrease the incidence of blood loss and postoperative complications, and is more in line with the concept of enhanced recovery after surgery (ERAS) (Azhar et al., 2016).

In this study, we noticed that the effect of TUPKP has a lot to do with the surgeon's proficiency. In advanced hospitals, the surgeon is more skilled in the operation of TUPKP and has a good surgical effect. In the primary hospitals, the surgeon's operational proficiency still needs to be further improved, and TUPKP still needs further promotion. Our study also had some limitations. First of all, the sample size was not large enough, probably not sufficient to produce powerful evidence, which might be false negative or positive. Secondly, this study only included subjects from one region in China, and the results may not be suitable for 
people in other regions or ethnic groups. This study adopted an observational design that may be affected by many factors, further weaken our findings. Next, no in-depth analysis was performed.

In conclusion, findings from this study suggest that whether to use Hemocoagulase Bothrops Atrox for Inject or not has no influence on the clinical parameters of $\mathrm{BPH}$ patients undergoing TUPKP. Moreover, adopting Hemocoagulase Bothrops Atrox for Inject can shorten prothrombin time, hospitalization time and probably might be safe among $\mathrm{BPH}$ patients undergoing TUPKP, achieving fine hemostasis and coagulation efficacy, and was not influenced by the size of prostate volume. High quality and larger samples studies should be operated, especially randomized controlled trials, to explore short-term and longterm effects in future.

\section{DATA AVAILABILITY STATEMENT}

The analyzed data sets generated during the study are available from the corresponding author on reasonable request.

\section{ETHICS STATEMENT}

The studies involving human participants were reviewed and approved by Committee for Ethical Affairs of the Zhongnan

\section{REFERENCES}

Ahmad, M., Khan, H., Aminullah, Masood, I., Masood, W., and Malik, A. (2016). Comparison of bipolar and monopolar cautry use in turp for treatment of enlarged prostate. J. Ayub Med. Coll. Abbottabad 28 (4), 758-761.

Autorino, R., Damiano, R., Di Lorenzo, G., Quarto, G., Perdona, S., D’Armiento, M., et al. (2009). Four-year outcome of a prospective randomised trial comparing bipolar plasmakinetic and monopolar transurethral resection of the prostate. Eur. Urol. 55 (4), 922-929. doi: 10.1016/j.eururo.2009.01.028

Azhar, R. A., Bochner, B., Catto, J., Goh, A. C., Kelly, J., Patel, H. D., et al. (2016). Enhanced recovery after urological surgery: a contemporary systematic review of outcomes, key elements, and research needs. Eur. Urol. 70 (1), 176-187. doi: 10.1016/j.eururo.2016.02.051

Babayan, R. K. (2018). "Development of Transurethral Resection of the Prostate (TURP)," in The History of Technologic Advancements in Urology. Eds. S. R. Patel, M. E. Moran, and S. Y. Nakada (Cham: Springer International Publishing), 49-57.

Bah, M., and Green, M. S. (2018). "Anesthesia for TURP," in Anesthesiology: A Practical Approach. Eds. B. G. Goudra, M. Duggan, V. Chidambaran, H. P. K. Venkata, E. Duggan, M. Powell, and P. M. Singh (Cham: Springer International Publishing), 845-850.

Berger, A. P., Wirtenberger, W., Bektic, J., Steiner, H., Spranger, R., Bartsch, G., et al. (2004). Safer transurethral resection of the prostate: coagulating intermittent cutting reduces hemostatic complications. J. Urol. 171 (1), 289-291. doi: 10.1097/01.ju.0000098925.76817.3a

Berger, A. P., Deibl, M., Leonhartsberger, N., Bektic, J., Horninger, W., Fritsche, G., et al. (2005). Vascular damage as a risk factor for benign prostatic hyperplasia and erectile dysfunction. BJU Int. 96 (7), 1073-1078. doi: 10.1111/j.1464-410X.2005.05777.x

Berry, S. J., Coffey, D. S., Walsh, P. C., and Ewing, L. L. (1984). The development of human benign prostatic hyperplasia with age. J. Urol. 132 (3), 474-479. doi: 10.1016/s0022-5347(17)49698-4

Botto, H., Lebret, T., Barre, P., Orsoni, J. L., Herve, J. M., and Lugagne, P. M. (2001). Electrovaporization of the prostate with the Gyrus device. J. Endourol. 15 (3), 313-316. doi: 10.1089/089277901750161917
Hospital of Wuhan University. The patients/participants provided their written informed consent to participate in this study.

\section{AUTHOR CONTRIBUTIONS}

B-HL, X-HW, and HZh designed this study. Z-JY, C-YW, X-DL and X-YR collected data. T-ZL re-checked data. B-HL and HZi performed analysis. B-HL and Z-JY wrote the manuscript. $\mathrm{X}-\mathrm{HW}$ and HZh reviewed the manuscript.

\section{FUNDING}

This work was supported by the National Key Research and Development Plan of China (2016YFC0106300) and Technical Innovation Major Program of Hubei province (2016ACA152), without any financial interest or benefit.

\section{ACKNOWLEDGMENTS}

The authors thank all the research members and the people who support investigators to perform this BPSC project, and all of the patients.

Chen, Y. B., Chen, Q., Wang, Z., Peng, Y. B., Ma, L. M., Zheng, D. C., et al. (2013) A prospective, randomized clinical trial comparing plasmakinetic resection of the prostate with holmium laser enucleation of the prostate based on a 2-year followup. J. Urol. 189 (1), 217-222. doi: 10.1016/j.juro.2012.08.087

Chen, S., Zhu, L., Cai, J., Zheng, Z., Ge, R., Wu, M., et al. (2014). Plasmakinetic enucleation of the prostate compared with open prostatectomy for prostates larger than 100 grams: a randomized noninferiority controlled trial with long-term results at 6 years. Eur. Urol. 66 (2), 284-291. doi: 10.1016/j. eururo.2014.01.010

Chughtai, B., Forde, J. C., Thomas, D. D., Laor, L., Hossack, T., Woo, H. H., et al. (2016). Benign prostatic hyperplasia. Nat. Rev. Dis. Primers 2, 16031. doi: $10.1038 /$ nrdp. 2016.31

de Medicis, E. (2014). From the Journal archives: Complications of transurethral prostatic surgery: back to the future? Can. J. Anaesth. 61 (3), 273-277. doi: 10.1007/s12630-013-0092-7

Dincel, C., Samli, M. M., Guler, C., Demirbas, M., and Karalar, M. (2004). Plasma kinetic vaporization of the prostate: clinical evaluation of a new technique. $J$. Endourol. 18 (3), 293-298. doi: 10.1089/089277904773582921

Doll, H. A., Black, N. A., McPherson, K., Flood, A. B., Williams, G. B., and Smith, J C. (1992). Mortality, morbidity and complications following transurethral resection of the prostate for benign prostatic hypertrophy. J. Urol. 147 (6), 1566-1573. doi: 10.1016/s0022-5347(17)37628-0

Dunsmuir, W. D., McFarlane, J. P., Tan, A., Dowling, C., Downie, J., Kourambas, J., et al. (2003). Gyrus bipolar electrovaporization vs transurethral resection of the prostate: a randomized prospective single-blind trial with $1 \mathrm{y}$ follow-up. Prostate Cancer Prostatic Dis. 6 (2), 182-186. doi: 10.1038/sj.pcan.4500631

El-Shaer, W., Abou-Taleb, A., and Kandeel, W. (2017). Transurethral bipolar plasmakinetic vapo-enucleation of the prostate: Is it safe for patients on chronic oral anticoagulants and/or platelet aggregation inhibitors? Arab. J. Urol. 15 (4), 347-354. doi: 10.1016/j.aju.2017.09.005

Eri, L. M., Thomassen, H., Brennhovd, B., and Haheim, L. L. (2002). Accuracy and repeatability of prostate volume measurements by transrectal ultrasound. Prostate Cancer Prostatic Dis. 5 (4), 273-278. doi: 10.1038/sj.pcan.4500568

Foster, S. A., Shortridge, E. F., DiBonaventura, M., and Viktrup, L. (2015). Predictors of self-reported benign prostatic hyperplasia in European men 
analysis of the European National Health and Wellness Survey. World J. Urol. 33 (5), 639-647. doi: 10.1007/s00345-014-1366-6

Gravas, S., Cornu, J. N., Drake, M. J., Gacci, M., Gratzke, C., Herrmann, T. R. W., et al. (2018). "EAU Guidelines on Management of Non-Neurogenic Male Lower Urinary Tract Symptoms (LUTS), incl. Benign Prostatic Obstruction (BPO) 2018," in European Association of Urology Guidelines, 2018 Edition (Arnhem, The Netherlands: European Association of Urology Guidelines Office).

He, L.-Y., Zhang, Y.-C., He, J.-L., Li, L.-X., Wang, Y., Tang, J., et al. (2016). The effect of immediate surgical bipolar plasmakinetic transurethral resection of the prostate on prostatic hyperplasia with acute urinary retention. Asian $\mathrm{J}$. Andrology 18 (1), 134-139. doi: 10.4103/1008-682X.157395

Ho, L. Y., Chu, P. S., Consigliere, D. T., Zainuddin, Z. M., Bolong, D., Chan, C. K., et al. (2018). Symptom prevalence, bother, and treatment satisfaction in men with lower urinary tract symptoms in Southeast Asia: a multinational, crosssectional survey. World J. Urol. 36 (1), 79-86. doi: 10.1007/s00345-017-2097-2

Huang, J. Y., Li, S., Yang, Z. H., Zeng, X. T., and Wang, X. H. (2015). Efficacy and Safety of Plasmakinetic Resection of the Prostate in Patients with a Prostate Gland Larger than 80 cc: 30-Month Follow-Up Results. J. Endourol. 29 (8), 925-928. doi: 10.1089/end.2014.0500

Jhanwar, A., Sinha, R. J., Bansal, A., Prakash, G., Singh, K., and Singh, V. (2017). Outcomes of transurethral resection and holmium laser enucleation in more than $60 \mathrm{~g}$ of prostate: A prospective randomized study. Urol. Ann. 9 (1), 45-50. doi: 10.4103/0974-7796.198904

Jiang, Y. L., and Qian, L. J. (2019). Transurethral resection of the prostate versus prostatic artery embolization in the treatment of benign prostatic hyperplasia: a meta-analysis. BMC Urol. 19 (1), 11. doi: 10.1186/s12894-019-0440-1

Joshi,S.A., Gadre, K.S.,Halli, R., andShandilya, R. (2014). Topicaluse of Hemocoagulase (Reptilase): A simple and effective way of managing post-extraction bleeding. Ann. Maxillofac. Surg. 4 (1), 119. doi: 10.4103/2231-0746.133082

Ketan, P. V., and Prashant, H. S. (2016). Thulium laser enucleation of the prostate is a safe and a highly effective modality for the treatment of benign prostatic hyperplasia - Our experience of 236 patients. Urol. Ann. 8 (1), 76-80. doi: 10.4103/0974-7796.171494

Koshiba, K., Egawa, S., Ohori, M., Uchida, T., Yokoyama, E., and Shoji, K. (1995). Does transurethral resection of the prostate pose a risk to life? 22-year outcome. J. Urol. 153 (5), 1506-1509. doi: 10.1016/S0022-5347(01)67447-0

Levi, M. M., Vink, R., and de Jonge, E. (2002). Management of bleeding disorders by prohemostatic therapy. Int. J. Hematol. 76 (Suppl 2), 139-144. doi: 10.1007/bf03165104

Li, S., Kwong, J. S., Zeng, X. T., Ruan, X. L., Liu, T. Z., Weng, H., et al. (2015). Plasmakinetic resection technology for the treatment of benign prostatic hyperplasia: evidence from a systematic review and meta-analysis. Sci. Rep. 5, 12002. doi: $10.1038 /$ srep 12002

Li, H., Huang, Y., Wu, X., Wu, T., Cao, Y., Wang, Q., et al. (2018). Effects of hemocoagulase agkistrodon on the coagulation factors and its procoagulant activities. Drug Des. Devel. Ther. 12, 1385-1398. doi: 10.2147/dddt.s159210

Littlejohn, J. O., Kang, Y. M., and Kaplan, S. A. (2004). “Transurethral Vaporization of the Prostate," in Management of Benign Prostatic Hypertrophy. Ed. K. T. McVary (Totowa, NJ: Humana Press), 195-210.

Liu, Z., Li, Y. W., Wu, W. R., and Lu, Q. (2017). Long-term Clinical Efficacy and Safety Profile of Transurethral Resection of Prostate Versus Plasmakinetic Resection of the Prostate for Benign Prostatic Hyperplasia. Urology 103, 198203. doi: 10.1016/j.urology.2017.02.006

Lu, X., Yang, X., Zhu, M., Hua, B., Niu, X., Xiao, W., et al. (2017). Hemostatic Effect of Hemocoagulase Agkistrodon on Surgical Wound in Breast Cancer Surgery. Zhongguo Yi Xue Ke Xue Yuan Xue Bao 39 (2), 183-187. doi: 10.3881/j. issn.1000-503X.2017.02.004

Lv, L., Wang, L., Fan, M., Ju, W., Pang, Z., Zhu, Z., et al. (2012). Two-year outcome of high-risk benign prostate hyperplasia patients treated with transurethral prostate resection by plasmakinetic or conventional procedure. Urology 80 (2), 389-394. doi: 10.1016/j.urology.2012.02.078

Mamoulakis, C., Ubbink, D. T., and de la Rosette, J. J. (2009). Bipolar versus monopolar transurethral resection of the prostate: a systematic review and meta-analysis of randomized controlled trials. Eur. Urol. 56 (5), 798-809. doi: 10.1016/j.eururo.2009.06.037

Martin, S. A., Haren, M. T., Marshall, V. R., Lange, K., and Wittert, G. A. (2011). Prevalence and factors associated with uncomplicated storage and voiding lower urinary tract symptoms in community-dwelling Australian men. World J. Urol. 29 (2), 179-184. doi: 10.1007/s00345-010-0605-8
Martis, G., Cardi, A., Massimo, D., Ombres, M., and Mastrangeli, B. (2008). Transurethral resection of prostate: technical progress and clinical experience using the bipolar Gyrus plasmakinetic tissue management system. Surg. Endosc. 22 (9), 2078-2083. doi: 10.1007/s00464-008-0008-8

Mebust, W. K., Holtgrewe, H. L., Cockett, A. T., and Peters, P. C. (1989). Transurethral prostatectomy: immediate and postoperative complications. A cooperative study of 13 participating institutions evaluating 3,885 patients. J. Urol. 141 (2), 243-247. doi: 10.1016/s0022-5347(17)40731-2

Meng, Q. Q., Pan, N., Xiong, J. Y., and Liu, N. (2019). Tranexamic acid is beneficial for reducing perioperative blood loss in transurethral resection of the prostate. Exp. Ther. Med. 17 (1), 943-947. doi: 10.3892/etm.2018.7025

Muslumanoglu, A. Y., Yuruk, E., Binbay, M., and Akman, T. (2012). Transurethral resection of prostate with plasmakinetic energy: 100 months results of a prospective randomized trial. BJU Int. 110 (4), 546-549. doi: 10.1111/j.1464-410X.2011.10770.x

Park, M. B., Hyun, D. S., Song, J. M., Chung, H. C., Kwon, S. W., Kim, S. C., et al. (2018). Association between the symptoms of benign prostatic hyperplasia and social disparities: Does social capital promote prostate health? Andrologia 50 (10), e13125. doi: 10.1111/and.13125

Petretski, J. H., Kanashiro, M., Silva, C. P., Alves, E. W., and Kipnis, T. L. (2000). Two related thrombin-like enzymes present in Bothrops atrox venom. Braz. J. Med. Biol. Res. 33 (11), 1293-1300. doi: 10.1590/s0100-879x2000001100005

Pickering, T. G., Hall, J. E., Appel, L. J., Falkner, B. E., Graves, J., Hill, M. N., et al. (2005). Recommendations for blood pressure measurement in humans and experimental animals: part 1: blood pressure measurement in humans: a statement for professionals from the Subcommittee of Professional and Public Education of the American Heart Association Council on High Blood Pressure Research. Circulation 111 (5), 697-716. doi: 10.1161/01. cir.0000154900.76284.f6

Qian, X., Liu, H., Xu, D., Xu, L., Huang, F., He, W., et al. (2017). Functional outcomes and complications following B-TURP versus HoLEP for the treatment of benign prostatic hyperplasia: a review of the literature and Metaanalysis. Aging Male 20 (3), 184-191. doi: 10.1080/13685538.2017.1295436

Qiu, M., Zhang, X., Cai, H., Xu, Z., and Lin, H. (2017). The impact of hemocoagulase for improvement of coagulation and reduction of bleeding in fracture-related hip hemiarthroplasty geriatric patients: A prospective, singleblinded, randomized, controlled study. Injury 48 (4), 914-919. doi: 10.1016/j. injury.2016.11.028

Ran, L., He, W., Zhu, X., Zhou, Q., and Gou, X. (2013). Comparison of fluid absorption between transurethral enucleation and transurethral resection for benign prostate hyperplasia. Urol. Int. 91 (1), 26-30. doi: $10.1159 / 000348793$

Reich, O., Gratzke, C., Bachmann, A., Seitz, M., Schlenker, B., Hermanek, P., et al. (2008). Morbidity, mortality and early outcome of transurethral resection of the prostate: a prospective multicenter evaluation of 10,654 patients. J. Urol. 180 (1), 246-249. doi: 10.1016/j.juro.2008.03.058

Saigal, C. S., and Joyce, G. (2005). Economic costs of benign prostatic hyperplasia in the private sector. J. Urol. 173 (4), 1309-1313. doi: 10.1097/01. ju.0000152318.79184.6f

Saluja, M., Masters, J., and Van Rij, S. (2018). "Open Simple Prostatectomy," in The Big Prostate. Eds. V. Kasivisvanathan, and B. Challacombe (Cham: Springer International Publishing), 143-152.

Speakman, M., Kirby, R., Doyle, S., and Ioannou, C. (2015). Burden of male lower urinary tract symptoms (LUTS) suggestive of benign prostatic hyperplasia (BPH) - focus on the UK. BJU Int. 115 (4), 508-519. doi: 10.1111/bju.12745

Starkman, J. S., and Santucci, R. A. (2005). Comparison of bipolar transurethral resection of the prostate with standard transurethral prostatectomy: shorter stay, earlier catheter removal and fewer complications. BJU Int. 95 (1), 69-71. doi: 10.1111/j.1464-410X.2005.05253.x

Vuichoud, C., and Loughlin, K. R. (2015). Benign prostatic hyperplasia: epidemiology, economics and evaluation. Can. J. Urol. 22 Suppl 1, 1-6.

Wang, K., Li, Y., Teng, J. F., Zhou, H. Y., Xu, D. F., and Fan, Y. (2015a). Transurethral plasmakinetic resection of the prostate is a reliable minimal invasive technique for benign prostate hyperplasia: a meta-analysis of randomized controlled trials. Asian J. Androl. 17 (1), 135-142. doi: 10.4103/1008-682x.138191

Wang, W., Guo, Y., Zhang, D., Tian, Y., and Zhang, X. (2015b). The prevalence of benign prostatic hyperplasia in mainland China: evidence from epidemiological surveys. Sci. Rep. 5, 13546. doi: 10.1038/srep13546 
Wei, J. M., Zhu, M. W., Zhang, Z. T., Jia, Z. G., He, X. D., Wan, Y. L., et al. (2010). A multicenter, phase III trial of hemocoagulase Agkistrodon: hemostasis, coagulation, and safety in patients undergoing abdominal surgery. Chin. Med. J. (Engl) 123 (5), 589-593. doi: 10.3760/cma.j.issn.0366-6999.2010.05.016

Wright, J. D., Ananth, C. V., Lewin, S. N., Burke, W. M., Siddiq, Z., Neugut, A. I., et al. (2014). Patterns of use of hemostatic agents in patients undergoing major surgery. J. Surg. Res. 186 (1), 458-466. doi: 10.1016/j.jss.2013.07.042

Wu, G., Hong, Z., Li, C., Bian, C., Huang, S., and Wu, D. (2016). A comparative study of diode laser and plasmakinetic in transurethral enucleation of the prostate for treating large volume benign prostatic hyperplasia: a randomized clinical trial with 12-month follow-up. Lasers Med. Sci. 31 (4), 599-604. doi: 10.1007/s10103-016-1883-1

Wu, L., Li, B. H., Wang, Y. Y., Wang, C. Y., Zi, H., Weng, H., et al. (2019). Periodontal disease and risk of benign prostate hyperplasia: a cross-sectional study. Mil. Med. Res. 6 (1), 34. doi: 10.1186/s40779-019-0223-8

Xie, C. Y., Zhu, G. B., Wang, X. H., and Liu, X. B. (2012). Five-year follow-up results of a randomized controlled trial comparing bipolar plasmakinetic and monopolar transurethral resection of the prostate. Yonsei Med. J. 53 (4), 734741. doi: 10.3349/ymj.2012.53.4.734

Yue, L., Wang, T., Ge, Y., Ge, M., Zhang, C., Hou, Q., et al. (2019). Prevalence and heritability of benign prostatic hyperplasia and LUTS in men aged 40 years or older in Zhengzhou rural areas. Prostate 79 (3), 312-319. doi: 10.1002/pros.23737

Zeng, X. T., Liu, T. Z., Gong, K., He, D. L., and Wang, X. H. (2018a). The BPSC: A prospective study investigating the clinical effect of interventional therapy and the risk factors for bladder cancer and benign prostatic hyperplasia in Chinese population. J. Evid. Based Med. 11 (1), 64-67. doi: $10.1111 /$ jebm. 12290

Zeng, X. T., Weng, H., Jin, Y. H., Liu, T. Z., Liu, M. Y., and Wang, X. H. (2018b). Association between Diabetes Mellitus and Hypertension in Benign Prostatic Hyperplasia Patients. Chin. Med. J. (Engl) 131 (9), 1120-1121. doi: 10.4103/0366-6999.230730

Zeng, X. T., Weng, H., Xiong, J., Huang, Q., Ma, L. L., Jin, Y. H., et al. (2018c). Comparison of Clinical and Physiological Parameters for Benign Prostatic
Hyperplasia in Hypertensive and Normotensive Patients. Front. Physiol. 9, 1330. doi: 10.3389/fphys.2018.01330

Zhang, K., Sun, D., Zhang, H., Cao, Q., and Fu, Q. (2015). Plasmakinetic vapor enucleation of the prostate with button electrode versus plasmakinetic resection of the prostate for benign prostatic enlargement $>90 \mathrm{ml}$ : perioperative and 3-month follow-up results of a prospective, randomized clinical trial. Urol. Int. 95 (3), 260-264. doi: 10.1159/000381753

Zhao, M. J., Huang, Q., Wang, X. H., Ren, X. Y., Jin, Y. H., and Zeng, X. T. (2019). Comparing clinical parameters of abnormal and normal fasting blood glucose in benign prostatic hyperplasia patients. Aging Male, 1-8. doi: 10.1080/13685538.2019.1570493

Zhou, H. B. (2017). Hypofibrinogenemia caused by hemocoagulase after colon polyps excision. Am. J. Case Rep. 18, 291-293. doi: 10.12659/ajcr.902059

Zi, H., Wang, X. J., Zhao, M. J., Huang, Q., Wang, X. H., and Zeng, X. T. (2019). Fasting blood glucose level and hypertension risk in aging benign prostatic hyperplasia patients. Aging (Albany NY) 11 (13), 4438-4445. doi: 10.18632/ aging.102061

Zou, Z., Xu, A., Zheng, S., Chen, B., Xu, Y., Li, H., et al. (2018). Dual-centre randomized-controlled trial comparing transurethral endoscopic enucleation of the prostate using diode laser vs. bipolar plasmakinetic for the treatment of LUTS secondary of benign prostate obstruction: 1-year follow-up results. World J. Urol. 36 (7), 1117-1126. doi: 10.1007/s00345-018-2229-3

Conflict of Interest: The authors declare that the research was conducted in the absence of any commercial or financial relationships that could be construed as a potential conflict of interest.

Copyright (c) $2019 \mathrm{Li}$, Yu, Wang, Zi, Li, Wang, Ren, Liu and Zheng. This is an openaccess article distributed under the terms of the Creative Commons Attribution License (CC BY). The use, distribution or reproduction in other forums is permitted, provided the original author(s) and the copyright owner(s) are credited and that the original publication in this journal is cited, in accordance with accepted academic practice. No use, distribution or reproduction is permitted which does not comply with these terms. 